\title{
Lepisma saccharina
}

\section{La historia onto-teo-lógica del Libro y la operación bibliofágica de la literatura}

\author{
GERMÁN OSVALDO PRÓSPERI Universidad Nacional de La Plata, Argentina \\ ORCID 0000-0002-3874-5871 \\ gerprosperi@hotmail.com
}

\section{Resumen}

La historia de la metafísica occidental, según una antigua tradición teológica, es una historia del Libro. En la segunda mitad del siglo XX, esta cuestión ha sido retomada entre otros por Jacques Derrida y Maurice Blanchot. El objetivo de este artículo es demostrar la siguiente tesis: la operación específica de la literatura con relación al Libro es análoga a la de un insecto llamado lepisma saccharina en relación con el papel. Esta analogía me permitirá mostrar que la perversión o la dislocación que efectúa la literatura en la estructura significativa del Libro va incluso más lejos que la gramatología derridiana.

Palabras clave: libro / literatura / fantasma / signo / lespisma saccharina / texto / escritura

\section{Lepisma saccharina. The onto-theo-logical history of the Book and the bibliophagic operation of Literature}

\section{Abstract}

The history of Western metaphysic is, according to an old theological tradition, a history of the Book. During the second half of 2oth century, Jacques Derrida and Maurice Blanchot, among others, revisited this issue. The aim of this article is to demonstrate that: the operation Literature performs on the Book is analogous to the operation the insect lepisma saccharina performs on paper. I will use this analogy to illustrate that perversion or dislocation performed by Literature on the significant structure of the Book is even more extensive than in Derrida's grammatology.

Key words: book / literatura / phantom / sign / lepisma saccharina / text / writing

Recibido: 12/11/2020. Aceptado: 15/2/2021

Para citar este artículo: Prósperi, G.O. (2021). Lepisma saccharina. La historia onto-teo-lógica del Libro y la operación bibliofágica de la literatura. El taco en la brea, (13) (diciembre-mayo). Santa Fe, Argentina: UNL. e0029 DOI: 10.14409/tb.v1i13.10221 


\section{Introducción}

La historia de la metafísica occidental, según una antigua tradición rabínica (o cabalista, con más propiedad) pero también cristiana e incluso, a partir del siglo XVI, científica en su sentido naciente, es una historia del Libro. ${ }^{1}$ Historia del Libro que supone, en consonancia con su naturaleza (es decir con su proveniencia) meta-física, dos libros o dos tomos de un único y ubicuo Volumen: el Libro de la Revelación y el Libro de la naturaleza, el códice sagrado y el códice profano, la Biblia y el Mundo: liber scripturae y liber naturae. ${ }^{2}$ Sería un error considerar la figura del Libro como una simple metáfora de lo Real, como una imagen, privilegiada tal vez pero decididamente fortuita, de la que se habrían servido los hombres para representarse el mundo y lo que está más allá del mundo; en suma, para dominarlo. Sería un error interpretarla como un mero símbolo, uno más entre los innumerables que han gozado alternativamente de mayor o menor fortuna a lo largo de los siglos. El Libro es el Ser: admitámoslo al menos de manera provisoria; admitámoslo incluso desde una perspectiva teológica. El mundo es la escritura de Dios. Reconozcámosle, además —o en consecuencia—, su pretensión de totalidad, su exigencia ontológica, su demanda de Ser, de ser el Ser, la totalidad del Ser, de albergar en sus páginas virtuales y reales lo Absoluto, en sus dos movimientos: despliegue y repliegue, desenvoltura y envoltura, desarrollo y enrollamiento.

En la segunda mitad del siglo XX, la cuestión del Libro como figura paradigmática de la ontoteo-logía ha sido retomada entre otros por Jacques Derrida, sobre todo a partir de una lectura de Edmond Jabès, y por Maurice Blanchot, con relación al Saber poshistórico anunciado por Alexandre Kojève en su famoso seminario de los años treinta en París sobre la Phänomenologie des Geistes. ${ }^{4}$ Ambos autores han intentado pensar la «clausura» del Libro, es decir los márgenes o las fisuras que permitirían abismar el Libro en su afuera: el texto o la escritura en el caso de Derrida, la obra o lo neutro en el caso de Blanchot.

En este artículo quisiera centrarme puntualmente en los análisis de Derrida y proponer una tesis —en realidad, una analogía — que puede parecer, prima facie, un tanto curiosa y desconcertante: la operación específica de la literatura con relación al Libro es análoga a la de un insecto llamado lepisma saccharina en relación con el papel. Esta analogía me permitirá mostrar que la perversión o la dislocación que efectúa la literatura en la estructura significativa del Libro va incluso más lejos que el «texto» derridiano. Para demostrar esto procederé en tres momentos: 1) explicaré rápidamente la posición de Derrida con relación al Libro y a su posible «clausura» o «afuera»; 2) explicaré las características del lepisma saccharina y por qué este insecto es sumamente pertinente para pensar la operación de la literatura al interior del Libro; 3) explicaré, también de forma escueta, las críticas de Giorgio Agamben a la filosofía de Derrida para mostrar la importancia de la barra que, en la estructura saussureana del signo, une y separa al significante del significado y a la vez la relación esencial que existe entre esa barra, la literatura y la imaginación. A lo largo del artículo, además, me apoyaré intermitentemente en algunos textos de Blanchot para pensar la especificidad de la literatura, sobre todo en su relación con la imagen (eidolon o phantasma) y con lo neutro.

\section{Il n'y a rien hors du texte?}

La filosofía posestructuralista, y particularmente Jacques Derrida, ${ }^{5}$ se ha interrogado obsesivamente sobre el afuera del Libro, ${ }^{6}$ sobre la posibilidad —y sobre la legitimidad de tal 
posibilidad— de pensar tan siquiera un afuera o, con mayor cautela, una clausura del Libro.? Se conoce la operación deconstructiva de la gramatología derridiana y su gesto paradójico: el Libro, lejos de ser el aliado natural de la escritura, sería más bien su enemigo, el disfraz protector de la onto-teo-logía ante la amenaza inasimilable del texto.

La idea del libro es la idea de una totalidad, finita o infinita, del significante; esta totalidad del significante no puede ser lo que es, una totalidad, más que si una totalidad de lo significado le preexiste, vigila su inscripción y sus signos, es independiente de su idealidad. La idea del libro, que reenvía siempre a una totalidad natural, es profundamente extranjera al sentido de la escritura. Ella es la operación enciclopédica de la teología y del logocentrismo contra la disrupción de la escritura, contra su energía aforística y, lo precisaremos más adelante, contra la diferencia en general. Si nosotros distinguimos el texto del libro, diremos que la destrucción del libro, tal como se anuncia hoy en todos los dominios, desnuda la superficie del texto. (Derrida, 1967a:30-31)

Derrida contrapone el texto, entendido como «tejido de signos [tissu de signes]» (1967a:26), al Libro. En efecto, este último no designa sino la organización o la estructuración —la jerarquía, en suma - del texto. De tal manera que la destrucción del Libro, envoltura y custodio absoluto del sentido, posibilitaría la emergencia del texto (de la œuvre, en Blanchot), juego de escritura, différance: producción inestable de diferencias. No obstante, como he dicho, el gesto decisivo de Derrida consiste en mostrar que, a fin de cuentas, el Libro es una forma históricamente legitimada del texto. El Libro es un texto que ha sido debidamente domesticado e introducido en la economía de la presencia. Y si a lo largo de la historia de la metafísica la escritura ha sido considerada subsidiaria o secundaria respecto de la voz, la cual pretendería asegurar en su intimidad espontánea la presencia del sentido y el sentido de la presencia, ${ }^{8}$ se trataría de mostrar que la voz, en verdad, no es sino una de las máscaras de la escritura; mostrar, en suma, que el Libro es un disfraz policial del texto. ${ }^{9}$ De tal manera que la voz, el Libro, no sería más que el repliegue de un afuera insondable pero necesariamente histórico: la escritura. ${ }^{10}$ Dicho de otro modo, si bien es cierto que para Derrida el texto es el «afuera» del Libro o la escritura el «afuera» de la voz, si cada vez que salimos del Libro nos abismamos en el texto, también es cierto que una vez caídos en el texto ya no hay salida, puesto que, sabemos, y lo sabemos por el mismo Derrida, «no hay nada fuera del texto [il n'y a rien hors du texte]» (1967a:233).

Pero es preciso señalar que el soporte de la escritura, como el texto, como el Ser, es también un tejido: de fibras vegetales, en el caso del papiro o del papel; de fibras animales, en el caso del pergamino. ${ }^{11}$ El entrelazamiento de las fibras que componen las hojas del libro, amén de la costura que las liga entre sí en el proceso de encuadernación, constituye un tejido trascendental respecto al texto en su sentido vulgar, es decir como tejido de signos (lingüísticos o no). Y es precisamente sobre este tejido material, sobre este soporte pre-significante que va a operar la literatura. Para comprender esto y señalar al mismo tiempo una sutil toma de distancia respecto al planteo derridiano explicaré someramente las características del lepisma saccharina.

\section{Lepisma saccharina}

Los bibliófilos conocen un pequeño insecto, procedente del orden de los tisanuros, de la familia lepismatidae, conocido como pececillo de plata o lepisma saccharina. A diferencia de otros 
animales herbívoros e incluso de los demás insectos xilófagos, el lepisma, cuya longitud no suele exceder el centímetro, es el único organismo, a excepción del molusco llamado Teredo navalis, que tiene la capacidad de producir celulasa, una enzima que degrada la celulosa (el biopolímero, por cierto, del que está hecho el papel). Los otros xilófagos consiguen aprovechar la celulosa gracias a una relación de simbiosis con ciertas bacterias y microorganismos que viven en sus tubos digestivos; el pececillo de plata, en cambio, digiere literalmente la celulosa, puesto que la celulasa rompe los enlaces que unen las glucosas que conforman dicho polímero. ${ }^{12}$

En su Micrographia: Or some Physiological Descriptions of Minute Bodies made by Magnifying Glasses, Robert Hooke nos proporciona uno de los primeros testimonios sobre el lepisma saccharina:

Este animal probablemente se alimenta de papel y de las cubiertas de los libros, perforándolos y creando varios agujeros redondos, encontrando alimento quizás en esta pulpa de cáñamo y lino (...); al parecer, la facultad digestiva de estas pequeñas creaturas es capaz de trabajar con estas substancias difíciles y de reducirlas a otra forma. (1665:209-210)

Resulta curioso que encontremos en este insecto - «el cual puede convertirse en un serio flagelo [advierte C.O. Clark] con relación a los textiles, papeles o materiales semejantes» (1927:190)— la operación específica de la literatura: la degradación o digestión del Libro de la historia occidental. Si la acción del Libro, como bien han señalado Derrida y Blanchot, no es sino aglutinar o cohesionar el tejido de lo Real y de la presencia, la acción —o des-acción, el désoeuvrement— de la literatura no es sino cortar o interrumpir, como la enzima $\beta$-1,4-glucanasa respecto a la cadena de 1,4- $\beta$-D-glucano del extremo no reductor de la molécula de celulosa, el entramado de la significación logo-antropo-falo-céntrica. El lepisma saccharina es al libro empírico lo que la literatura es al Libro teológico-metafísico. En otras palabras, la literatura es el lepisma saccharina del Libro de la historia occidental — que es, desde luego, una historia del Libro- Si el Libro, en tanto escrito por Dios y/o el Hombre (las dos figuras metafísicas del escritor, los dos grandes textores), garantiza la proliferación de celulosa, la literatura, en tanto lepisma, la digiere. La celulasa, en este sentido, se convierte en el peligro esencial de la onto-teo-logía. El lepisma saccharina, la literatura, tiene la capacidad de digerir la presencia. De allí el aparato de costura implementado por la onto-teo-logía. Se trata siempre de zurcir o rellenar los huecos y rasgaduras producidos por el efecto de la celulasa. La relación entre el Libro y la literatura es análoga a la que existe entre la celulosa y la celulasa. En suma, la literatura es la celulasa que rompe los enlaces de celulosa que componen el tejido, el textus, de la historia de la metafísica occidental. La digestión del lepisma nos abisma en el corazón del afuera.

Ahora bien, en la medida en que la operación efectuada por la literatura consiste en hendir o desgarrar el entramado del texto, y no simplemente del Libro, sus efectos van más allá incluso que el proyecto derridiano. Por tal motivo, si bien la literatura como interrogación absoluta, reconoce Derrida, «no pertenecería jamás a ningún libro» (1967b:116) pero por eso mismo se inscribiría siempre en las huellas de una archi-écriture, siempre en el entramado de un texto, del cual no existe —recordémoslo— afuera, es preciso mostrar los agujeros y las rasgaduras que acosan, no ya al Libro, sino a su «afuera», al texto mismo. En suma, si «la clausura del libro» es sinónimo de «la abertura del texto» (1967b:429) o, lo que es lo mismo, si «la cuestión de la escritura sólo puede 
abrirse a libro cerrado» (1967b:429), si «entre Dios y Dios, entre el Libro y el Libro (...) la escritura vela» (1967b:429), no la escritura en su sentido vulgar, desde luego, sino como différance, como «la sombra del libro» (1967b:436), es preciso mostrar las hendiduras o las fracturas que escanden la trama de la différance misma, que se sustraen a la economía lúdica de la diferencia, a la operación subversiva del texto. En las heridas del tejido histórico, del Libro pero también del texto, ni siquiera vela la escritura, esa «(pura) forma de exterioridad», en palabras de Blanchot (cfr. 1969:632). La literatura, en este sentido, es el hueco al interior de la différance, la suspensión de la archi-écriture, el descalabro incluso de ese jeu insensé d'écrire (Mallarmé) que para Blanchot apuntaba ya, titubeante, a la ausencia de Libro. Si el texto es el afuera del Libro, la literatura es el —o, más bien, apunta al— afuera del texto, que para Derrida no existe. ${ }^{13}$

Se comprenderá entonces que la literatura efectúa una operación que afecta fundamentalmente a la dimensión trascendental del Libro. Si, como sostiene Blanchot, «el libro es el a priori del saber» (1969:621), entonces las rasgaduras y los agujeros del Libro son lesiones en el espacio trascendental de la historia. No se trata solo de rupturas en el nivel empírico de los signos, en las eventuales actualizaciones significantes, sino de verdaderos desgarros en la superficie de inscripción del texto histórico. Según Derrida, la superficie de inscripción no es el Libro sino el texto o la escritura. Y si el Libro, el a priori del saber, no es más que una forma legitimada históricamente del texto, entonces éste es el a priori de aquél, el a priori del a priori. ${ }^{14}$ Sin embargo, en mi opinión, la dehiscencia producida por la literatura en el tejido del Libro no implica —o no solo implica — un descubrimiento del —o una caída en el— texto, como sugiere Derrida. La herida es demasiado profunda: atraviesa libro y texto, phone y gramma, a priori y a priori del a priori. Por ese motivo, la dehiscencia no puede ser considerada, frente a la relación analógica del libro/voz con el alma, como una reivindicación —ni siquiera estratégica y momentánea— del cuerpo, sino como algo más abominable, como lo abominable: el fantasma. ${ }^{15}$ Por el contrario, Derrida afirma en De la Grammatologie:

\footnotetext{
la escritura, la letra, la inscripción sensible han siempre sido consideradas por la tradición occidental como el cuerpo y la materia exteriores al espíritu, al aliento, al verbo y a su logos. Y el problema del alma y del cuerpo es sin duda derivado del problema de la escritura al cual parece —inversamente — prestar sus metáforas. (1967a:52)
}

Derrida propone la siguiente analogía: la escritura es al cuerpo lo que la voz es al alma, o, también, el texto es al cuerpo lo que el Libro es al alma. ${ }^{16}$ Se notará, entonces, la especificidad de la literatura: hiende el Libro, la voz, el alma, el espíritu, pero en vez de restituir sus derechos al texto, a la escritura, al cuerpo, a la carne, profundiza la hendidura y atraviesa incluso la materialidad que le sirve de soporte. Por eso la rasgadura es tanto empírica como trascendental, tanto espiritual como corporal, tanto inteligible como sensible. A través de ella accedemos a ese effondement universel del que habla Deleuze (cfr. 1968:98), por ella nos abismamos en el dominio de los sueños y de la muerte - que siempre han poseído una relación esencial, incluso para los mismos Derrida y Blanchot, con el espace littéraire —, no para encontrar allí, por cierto, la espesa materialidad de los cuerpos, tampoco la etérea inteligibilidad de los espíritus, sino la paradójica neutralidad del fantasma. ${ }^{17}$ No es casual, por cierto, que hacia el final del ensayo "L'absence de livre», Blanchot identifique a la escritura (equivalente aquí a la literatura) con la noción teológica 
de eidolon, la cual se opone, en la tradición platónico-cristiana, a eikon: «Escribir, si escribir es relacionarse con la imagen y llamar al ídolo [l'idole], escribir se inscribe fuera de la exterioridad que le es propia, exterioridad que la escritura rechaza esforzándose por colmarla, tanto por el vacío del signo como por la pura significación del signo» (1969:635).

Es preciso entender correctamente el punto que estoy intentando señalar respecto a la deconstrucción derridiana: no se trata de afirmar que la propuesta de Derrida consiste simplemente en invertir las oposiciones o las jerarquías dominantes (por ejemplo, afirmar el cuerpo sobre el alma, el texto sobre el libro, el gramma sobre la phone, etc.). En efecto, la estrategia derridiana consiste en recuperar el elemento marginado o supuestamente intrascendente pero solo con el objetivo de dislocar o suspender la oposición en cuanto tal. Basta recordar la conferencia pronunciada en la Société française de philosophie el 27 de enero de 1968, en la que Derrida identificaba a la différance con un «orden que resiste a la oposición fundadora de la filosofía entre lo sensible y lo inteligible» (1972:5), razón por la cual se ubica «entre palabra y escritura» (1972:5). La operación de la différance, explicaba también Derrida en una maniobra estratégica que emparentaba su neologismo con lo neutro blanchotiano, recuerda algo similar a la voz media, en tanto «no se deja pensar ni como pasión ni como acción de un sujeto sobre un objeto, ni a partir de un agente ni a partir de un paciente, ni a partir ni en vista de ninguno de estos términos» (1972:9). En este sentido, Mónica B. Cragnolini ha explicado el doble gesto de la deconstrucción con notable lucidez:

La deconstrucción no consiste ni en una destrucción de las estructuras binarias (que plantearía un monismo metafísico) ni en una inversión de dichas estructuras (que repetiría «al revés» ese dualismo). Es cierto que la tarea de la «solicitación» supone, en algún momento la inversión (...) De allí esos juegos derridianos, en los que lo marginal, lo suplementario, lo no importante, pasa a ocupar un lugar diverso, no por mera inversión, sino ejercitando la inversión como uno de los modos de la mostración de la poca importancia de las jerarquías de los opuestos. (2012:21-22)

Mi intención, por lo tanto, no es identificar el proyecto deconstructivo propuesto por Derrida con una mera inversión de las oposiciones, descuidando así el momento de indecidibilidad y de dislocación de esas estructuras polares, sino más bien señalar que esa indecidibilidad es siempre pensada en términos de différance, es decir como una proliferación de diferencias sin origen ni fin. En este sentido, mi lectura de Derrida se basa de algún modo, como se verá en el apartado siguiente, en la crítica formulada por Giorgio Agamben al proyecto gramatológico. Es preciso decir que la lectura de Agamben ha sido considerada por varios autores injusta e imprecisa, sobre todo porque pareciera concentrarse en uno de los momentos de la deconstrucción, la inversión de las jerarquías, y descuidar el momento de suspensión y desarticulación. ${ }^{18}$ Considero que es una observación válida y que Agamben, en efecto, tiende a descuidar este segundo momento del proceso deconstructivo. Sin embargo, también es cierto, como dije, que Derrida piensa a la desactivación de las oposiciones en términos de différance, es decir como un juego de diferencias que imposibilita cualquier constitución fundacional, así como invalida la primacía de un término sobre el otro, mientras que la propuesta de este artículo es mostrar que el gesto extremo de la literatura consiste en suspender incluso ese juego o esa economía, es decir horadar el mismo proceso diferencial denotado por el concepto (que no es un concepto) différance, lo cual para Derrida sería imposible porque no existe para él un afuera del texto o de la différance, sino 
que el texto o la différance son el afuera. En uno de los estudios más minuciosos de la relación, muchas veces polémica o por lo pronto crítica, entre Derrida y Agamben, Kevin Attell ha explicado esta supuesta «deficiencia» en el planteo derridiano según la óptica de Agamben con palabras esclarecedoras. Refiriéndose a la lectura que realizan ambos filósofos de «Zur Kritik der Gewalt», el célebre ensayo de W. Benjamin, ${ }^{19}$ Attell explicita las diferencias entre ambas posiciones y, al hacerlo, muestra indirectamente aunque con gran claridad lo que estoy intentando sugerir en este artículo. Cito el pasaje que me interesa:

Para Derrida, la indetenible oscilación y contaminación entre los términos polares sostienen al sistema binario en una topología diferencial que no puede ser nunca remitida a un fundamento final u originario (excepto el no-fundamento de la alteridad ética y la responsabilidad del Otro). Esta oscilación también revela que el concepto de origen mismo se encuentra inscripto en una lógica de la iterabilidad. Para Agamben, por el contrario, el núcleo del análisis de Benjamin —y por supuesto, de su propio esfuerzo - consiste en separar definitivamente lo que ha sido forzosamente (soberanamente) articulado a fin de abrir un espacio no jurídico para la acción humana. (2015:137)

Mi tesis es que la operación que efectúa la literatura al interior del Libro abre a un afuera análogo a lo que Attell, siguiendo a Agamben, llama un «espacio no jurídico». Así como las nociones de «uso» o de «juego» designan para Agamben un espacio no jurídico de acción, es decir un afuera respecto a la Ley y al derecho, asimismo la literatura designa un espacio no diferencial, un afuera de la différance misma, es decir del texto. ${ }^{20} \mathrm{El}$ «uso» o la «profanación» de la Ley no designan en este sentido solo una indecidibilidad, un diferimiento o una contaminación entre dos términos polares, sino un afuera de esa misma proliferación diferencial en la que se asienta la oposición binaria. Pero consideremos con más detalle la crítica de Agamben.

\section{La barra del signo}

Agamben, sin duda, es uno de los pensadores contemporáneos que más ha insistido en la insuficiencia del proyecto derridiano a la hora de «superar» la historia de la metafísica. Ya en un texto temprano como Stanze. La parola e il fantasma nella cultura occidentale, Agamben decía lo esencial:

Poner en el inicio una escritura y un rastro significa poner el acento en esa experiencia original, pero no por cierto superarla. Gramma y phone pertenecen en efecto ambos al proyecto metafísico griego, que, calificando de "gramática» a la reflexión sobre el lenguaje y concibiendo la phone como semantike (o sea como signo de una «escritura del alma»), ha pensado desde el comienzo el lenguaje desde el punto de vista de la «letra». La metafísica de la escritura y del significante no es sino la otra cara de la metafísica del significado y de la voz, el venir a la luz del fundamento negativo y no por cierto su superación. (1979:187)

Tres años después de la publicación de Stanze, en el seminario Il linguaggio e la morte, Agamben volvía a insistir en la imposibilidad de superar la metafísica profundizando la vía negativa, inherente - según el autor — a la misma tradición que se pretendía deconstruir. En la «ottava giornata», por ejemplo, aludía al «límite de toda crítica de la metafísica - y tales son tanto la filosofía de la diferencia como el pensamiento negativo y la gramatología - que piensa traspasar su horizonte radicalizando el problema de la negatividad y de lo infundado» (1982:105). ${ }^{21} \mathrm{Al}$ 
contrario, según Agamben no se trata de afirmar el significante o la escritura sobre el significado o la voz, sino de "reconocer la situación originaria del lenguaje, ese "plexo de diferencias eternamente negativas", en la barrera resistente a la significación» (1979:188). Tal es así que Agamben identifica a lo humano, en un claro gesto antropocéntrico acaso heredado de Heidegger, con esa fractura en la que se fundan los dos elementos del signo:

\footnotetext{
El núcleo originario del significar no está ni en el significante ni en el significado, ni en la escritura ni en la voz, sino en el pliegue de la presencia sobre el que estos se fundan: el logos, que caracteriza al hombre en cuanto zoon logon echon, es ese pliegue que recoge y divide cada cosa en la «conmesura» de la presencia. Y el humano es precisamente esa fractura de la presencia, que abre un mundo y sobre el cual se sostiene el lenguaje. El algoritmo S/s debe reducirse por eso a la sola barrera: — (1979:188)
}

Agamben explica que esta estructura dual (meta-física) ha gobernado implícitamente la interpretación del significar como unidad de un significante y un significado desde la Antigüedad greco-latina hasta la lingüística y la semiología modernas. La definición del signo como «unidad lingüística de una cosa doble, hecha de la aproximación de dos términos» propuesta por Ferdinand de Saussure (cfr. 1995:98) en el célebre Cours de linguistique générale constituye en cierto sentido su fórmula paradigmática. El signo mantiene unidos el significante y el significado según su eje vertical y a la vez instaura una distinción, una barra: - , según su eje horizontal. En este sentido, Saussure puede decir que el signo «es una entidad psíquica de dos caras» (1995:99). Como Cristo, según su naturaleza hipostática, el signo une sin confundir y distingue sin separar. Por eso mismo no se trata solo de restituir los derechos del significante, del gramma (como propone en cierta forma Derrida, al menos en un primer momento de la deconstrucción), sino de abismarse en la barrera o el pliegue, no ya para descubrir allí el nexo meramente conjuntivo implementado por el dispositivo del Libro, sino también —y sobre todo— la dehiscencia disyuntiva introducida por la literatura. Nótese entonces que los huecos o las hendiduras provocadas por el Lepisma, según la analogía planteada, conciernen específicamente al espacio extra-ontológico establecido por la barra del signo. ${ }^{22}$ No es por eso casual que Agamben identifique a lo simbólico y lo diabólico con los dos movimientos del significar y por ende de la metafísica occidental en cuanto tal:

En cuanto que en el signo está implícita la dualidad del manifestante y de la cosa manifestada, es en efecto una cosa fragmentada y doble, pero en cuanto que esa dualidad se manifiesta en el único signo, éste es por el contrario una cosa conjunta y unida. Lo simbólico, el acto de reconocimiento que reúne lo que está dividido, es también lo diabólico que continuamente transgrede y denuncia la verdad de ese conocimiento. (1979:160; las cursivas son de Agamben)

La tesis que quisiera sugerir es que el Libro funciona como symbolon, es decir como fuerza conjuntiva o aglutinante de los dos elementos del signo —y, más allá, de las dos regiones de la metafísica en general: inteligible/sensible, espíritu/materia, alma/cuerpo, etc.-, a la vez que la literatura funciona como diabolon, es decir como fuerza disyuntiva o como escisión entre ambos elementos. Si el Libro es esencialmente simbólico, la literatura es diabólica. El Libro es el espacio -el a priori textil— que sostiene la cadena de signos y asegura así el proceso semántico. Cada signo, en efecto, es un punto de tejido en la trama de la significación. Se comprenderá 
ahora la radical catástrofe generada por el efecto de la literatura, y a la vez su condición irreductible a cualquier forma de antropocentrismo. No solo rompe el lazo o la aglutinación del significado y el significante, sino la misma cadena semiótica, al igual que la enzima $\beta$-1,4-glucanasa respecto a la cadena de 1,4- $\beta$-D-glucano en el proceso digestivo del Lepisma sacchari$n a .^{23} \mathrm{La}$ circulación del sentido se suspende, caen los dos ejes del signo, el vertical que unía sin confundir y distinguía sin separar al significado del significante, y el horizontal que unía sin confundir y distinguía sin separar un signo de otro signo. Lo cual no quiere decir, desde luego, que la literatura no tenga que ver con el registro simbólico y con el nivel semántico. La escritura literaria utiliza por cierto signos y cadenas significantes, pero se trata más bien de una parodia cuyo gesto último y específico, es decir diverso al de la escritura corriente o habitual, consiste en efectuar una disyunción en el corazón del signo. Por eso Deleuze no ha dejado de señalar que la literatura crea una lengua extranjera que se define, en última instancia, por un «límite asintáctico hacia el que tiende todo el lenguaje» (1993:16). De tal modo que el gesto extremo de la literatura consistiría en la conquista de «Visiones y Audiciones que ya no pertenecen a ninguna lengua» (1993:16). Es el momento en el que «el lenguaje soporta una presión que lo remite al silencio» (1993:142); momento sublime en el que «el lenguaje entero revela su afuera, más allá de toda sintaxis» (1993:16-17).24

En relación con esta contraposición entre sym-bolon y dia-bolon quisiera mencionar un artículo de Mónica Cragnolini en el cual no solo se señala la dehiscencia o separación específica de lo diabólico sino que se sugiere también su relación intrínseca con el tejido y el texto:

Si el sym-bolo era la unión de las dos partes de la moneda a partir de las cuales se re-conocían los portadores de las mismas (y desde allí podían tejer una historia), el dia-bolos ha de ser justamente el camino inverso: la separación después de la unión, la ruptura de la significación, la historia des-tejida, la falta de re-conocimiento, el des-conocimiento, la falta del sentido, la locura, la pérdida de la identidad. (1996:195)

El Libro teje la historia de la metafísica o, mejor aún, Dios y/o el Hombre, los grandes textores (escritores/tejedores) del Libro de Occidente, tejen la trama del Sentido histórico, mientras que la literatura desteje ese entramado, hace delirar la narrativa y la significación —la significación de la narrativa - e introduce la locura y la opacidad en el seno del Libro. Al Symbolos divino, onto-teo-lógico, se le opone así el Diabolos espurio, paródico y decididamente ambiguo. Si Dios primero y el Hombre después fueron los encargados de mantener suturada la herida semiótica y metafísica, la literatura, eminentemente diabólica, abre la herida, el trauma, y en el mismo movimiento diluye a esos dos grandes tejedores y suturadores, esas dos figuras paradigmáticas del Fundamento. Esta operación disyuntiva de la literatura supone una apertura a lo que Blanchot ha llamado lo neutro. No sorprende, sin duda, que Blanchot haya identificado a ese concepto con el lugar, más allá o más acá de todo lugar, de los fantasmas:

Neutro sería el acto literario que no es ni de afirmación ni de negación y (en un primer tiempo) libera el sentido como fantasma, acoso, simulacro de sentido, como si lo propio de la literatura fuese ser espectral, no acosada por sí misma, sino porque acarrearía este previo de todo sentido que sería su acoso, o más fácilmente porque se reduciría a no ocuparse de nada más que de simular la reducción de la reducción, sea o no fenomenológica. ${ }^{25}$ (1969:449) 
Esta condición espectral de la literatura no es un mero avatar o un rasgo más entre los muchos que se podrían predicar de ella. Se trata de un elemento constitutivo y esencial. La literatura es esencialmente espectral o fantasmática. Este último enunciado no es incompatible -más bien al contrario - con la posición derridiana. La diferencia consiste en el modo de entender lo espectral o fantasmático: como différance o pharmakon, en Derrida; como afuera extraontológico o suspensión de la différance (y de las oposiciones, por supuesto), en mi caso. Dicho de otro modo: mientras que la literatura para Derrida nos abisma en un afuera relativo (al juego diferencial que se produce en ese afuera, que es ese afuera), para mí la literatura nos abisma en un afuera absoluto, irreductible e inasimilable, no solo a las oposiciones que estructuran la metafísica de la presencia, sino a todo juego y a toda diferencia. En este punto, convendría recuperar las especulaciones de Fabián Ludueña Romandini acerca de su espectrología posmetafísica y de la distancia que lo separa de - al mismo tiempo que lo acerca a - la hantología derridiana: «Sólo una espectrología post-deconstruccionista y, por lo tanto, en pleno derecho también post-metafísica podrá dar cuenta de la geografía y de la fisiología de los espectros» (2016:208); y un poco más adelante: «Una tarea de esta índole indica, con todo, dar un paso a partir de la deconstrucción pero, también, más allá de ella hacia una ciencia de lo espectral en cuanto tópos in-sistente por fuera de toda fenomenología de la vivencia» (2016:209). Creo que la distancia que toma Ludueña respecto de la deconstrucción derridiana en lo que concierne a la espectrología es análoga, en cierto sentido y salvando las evidentes diferencias, a la que tomo en este artículo respecto a la posición de Derrida en lo concerniente a la literatura. En este sentido, la noción de literatura espectral o fantasmática aquí propuesta, si bien conserva muchos puntos en común con la hantología derridiana, difiere en otros puntos no menos esenciales. La figura del Lepisma es también, como la espectrología de Ludueña, poshantológica. ${ }^{26}$

\section{Conclusión}

A lo largo de este artículo he mostrado: 1) que la gramatología de Derrida se caracteriza, en un primer momento, por una preeminencia del significante sobre el significado o de la escritura sobre la voz, es decir del texto sobre el Libro, y en un segundo momento por dislocar esa polaridad y reinscribirla en el espacio proliferante de la différance; 2) que la figura del Lepisma saccharina permite pensar en profundidad la operación disruptiva y subversiva que define a la literatura en relación con el Libro; y 3) que los dos movimientos contrapuestos del Libro y de la literatura, uno conjuntivo y simbólico, el otro disyuntivo y diabólico, conciernen a la barra que une y separa, en el signo, el significante y el significado.

Ahora bien, la importancia de la figura del Lepisma saccharina consiste en que no solo produce una fractura o un hueco que interrumpe la cadena significante (que ya es un afuera del significado), sino que horada el soporte mismo sobre el cual se apoyan los significantes. Por eso la literatura, como el Lepisma, digiere la superficie trascendental de la significación, tanto el registro de los significados como el de los significantes. Esto quiere decir que la literatura provoca huecos o hendiduras - traumas - en el a priori del saber. Si para Derrida el afuera del Libro es el texto y por consiguiente la función de la literatura es hendir el libro y abismarlo en su afuera, en la différance de la escritura, para mí la función extrema de la literatura consiste no solo en lacerar al Libro sino también al texto, el cual, como lo indica su etimología, no deja de ser un tejido (de diferencias y diferimientos). La figura del Lepisma es interesante, en este 
sentido, porque genera heridas no solo en la escritura sino en el soporte de la escritura, en la página en cuanto tal, es decir en el tejido de fibras vegetales que es por ejemplo el papiro o el papel o en el tejido de fibras animales que es el pergamino. Dicho en otras palabras: la literatura genera un corte no solo en el afuera del Libro, que para Derrida coincide con el texto, sino en el texto mismo, en el soporte trascendental en cuanto tal. A este movimiento de disyunción radical, de disyunción trascendental —o, habría que decir, retomando los términos del propio Derrida, cuasi-trascendental—, ${ }^{27}$ le corresponde el calificativo de diabólico. Si la literatura es esencialmente diabólica es porque separa las dimensiones que el signo (y, más allá, la metafísica en cuanto tal) había pretendido suturar. Estas dos dimensiones son por supuesto el significado y el significante en el nivel semiótico, el alma y el cuerpo en el nivel antropológico y lo inteligible y lo sensible en el nivel ontológico. Derrida, por cierto, está a la vez cerca y lejos de la disyunción diabólica: cerca porque indica la necesidad de dislocar las oposiciones y las jerarquías; lejos porque esa dislocación pasa siempre por la indecidibilidad de la différance. Es como si Derrida tejiera los huecos producidos por el Lepisma con el tejido infundado de los diferimientos, mientras que para mí se trata de suspender el juego textil y diferencial y de abismarse en un dominio absolutamente otro en donde ni siquiera es posible hablar ya de tejido o de diferimientos lúdicos. Ahora bien, ¿cómo pensar entonces la operación de la literatura en términos ontológicos? Por razones de extensión, solo puedo sugerir aquí el gesto radical que define a la literatura en este sentido. Si la metafísica en general, y estoy simplificando adrede, ha reconocido —y jerarquizado, por supuesto— dos órdenes ontológicos: lo sensible y lo inteligible o la materia y el espíritu, órdenes que se expresan, al nivel del signo, en el significante y el significado respectivamente, y si lo propio de la literatura es separar ambos niveles, es decir producir una herida o una fractura en la barra que distingue ambos elementos, entonces el espacio abierto por esa operación disyuntiva solo puede ser pensado, en los términos de la propia metafísica, como un Extra-Ser. No deja de ser crucial que el lugar que ocupa la barra en la estructura del signo es el lugar que ha ocupado la imaginación y la imagen en la estructura de lo Real a lo largo de la historia de la filosofía. Por eso Agamben puede indicar las «insuficiencias» de la gramatología derridiana, señalar la importancia de la barra y, en el mismo texto, analizar el rol del phantasma en la tradición medieval y su función decisiva en la poesía del dolce stil novo. En efecto, el phantasma es el elemento que surge cuando la sensibilidad y el intelecto se desactivan. De allí, estimo, el nexo que existe en el pensamiento de Blanchot entre las imágenes, el afuera y lo neutro:

[la imagen] corre el riesgo constantemente de reenviarnos, no ya a la cosa ausente, sino a la ausencia como presencia, al doble neutro del objeto en el cual la pertenencia al mundo se ha disipado: esta duplicidad no puede ser pacificada por un o bien o bien, capaz de autorizar una elección y de sustraer de la elección la ambigüedad que la vuelve posible. Esta duplicidad reenvía a un doble sentido siempre más inicial. (1955:353)

No sorprende entonces que exista un vínculo esencial, que trasciende sin duda a la obsesión romántica, entre la literatura y el sueño. Como este, la literatura es el dominio específico de los phantasmata. Por eso he indicado que Dios y el Hombre han sido las dos grandes figuras que, a lo largo de la historia onto-teo-lógica que es una historia del Libro, se han encargado de sellar 
o suturar el hiato entre lo sensible y lo inteligible o entre el cuerpo y el alma, que es el lugar específico de las imágenes y la imaginación. En este sentido, la operación del Libro puede ser caracterizada como un destierro del phantasma o como una usurpación de su lugar "propio». Por eso Cristo se presentará como eikon, como ícono, como (la) imagen consubstancial del Padre, y el Hombre como creado a su imagen y semejanza (ad imaginem et similitudinem Dei, según la nomenclatura latina). Esta operación onto-teo-lógica consiste entonces en una «desneutralización» o una «domesticación de lo neutro»:

se podría reconocer, en toda la historia de la filosofía, un esfuerzo ya sea para aclimatar y domesticar lo «neutro» substituyéndole la ley de lo impersonal y el reino de lo universal, ya sea para rechazar lo neutro afirmando la primacía ética del Yo-Sujeto, la aspiración mística a lo Único singular. Lo neutro es así constantemente eliminado de nuestros lenguajes y de nuestras verdades. (1969:441)

Este movimiento de desneutralización consiste así en reemplazar al phantasma por el eikon, al eidolon por el zoon logon echon, al diabolon por el symbolon. ${ }^{28}$ Pero detengo aquí estas reflexiones que merecerían ser desarrolladas en otro escrito o en el marco de un libro. En suma, la idea de este artículo ha sido simplemente señalar, a partir de algunas indicaciones de Derrida, Agamben y Blanchot, la especificidad y la radicalidad que posee la operación literaria. De algún modo, la literatura nos muestra, como el Lepisma saccharina respecto al papel, que hay incluso un afuera del texto, y que ese afuera es por necesidad extra-ontológico.

\section{Notas}

1 Sobre la concepción cabalista del Libro, cfr. Scholem, 1998:35-94; Idel, 2002; 1989:29-81. Sobre la concepción cristiana del Libro, cfr. Tanzella-Nitti, 2001:85-92; 2005:235-248. Sobre la concepción de la naturaleza como un Libro en la ciencia moderna, especialmente en Galileo, cfr. Brooke, 2014:103-107.

2 Para un panorama general de estos dos libros, cfr. Curtius, 1983:302-347.

3 Hans Blumenberg, por el contrario, ha interpretado la figura del Libro como una metáfora de la legibilidad del mundo: «En estas metáforas — dice Blumenberg- no se trata de verdades últimas, de ontología o historias del ser o de metafísica. En ellas nos encontraremos con lo interpretable (...) Con esta determinada indeterminación tiene que ver la metafórica de la experimentabilidad del mundo, para la cual está el paradigma de la «legibilidad»» (1984:10). En este artículo, sin embargo, sí se tratará de ontología, de historia del ser y de metafísica; no, claro, en lo que estos tópicos tienen de dogmático, sino en lo que tienen de específicamente disruptivo. Más que el libro, veremos, me interesarán sus rasgaduras y sus agujeros.
4 En efecto, Kojève explicaba en su seminario: «la Historia ha terminado, ya no hay nada más por hacer, y sólo se es Hombre si se lee y comprende el Libro que revela todo lo que ha sido y podía haber sido hecho» (1979:358). Por otra parte, este Libro (biblos, en griego), en tanto encarnación del absolute Wissen, encontraba su figura paradigmática en la Biblia: «este Libro ("Biblia”) es el Logos eterno encarnado» (1979:411).

5 Resulta más que evidente que, en este punto, existe una clara influencia de la tradición judía en el pensamiento de Derrida. Sobre este asunto, cfr. Idel, 2003:133-156. En dicho ensayo, Idel sostiene, en efecto, que una de las fuentes de inspiración del filósofo franco-argelino «se encuentra en los textos cabalistas» (2003:134). Dos puntos, según Idel, resultan esenciales en este sentido: «El primero consiste en la afirmación de que no hay nada fuera del texto. El segundo concierne a la yuxtaposición de un modo de pensamiento fundado en el texto y heredado de fuentes judías con un abordaje filosófico, es decir logocéntrico, que es de origen griego» (2003:134). 
6 ¿Acaso no ha dicho Maurice Blanchot «que lo que obsesiona al libro (lo que lo acosa), sería esta ausencia de libro que siempre falta» (1969:630)?

7 Sobre la clausura del Libro, cfr. Derrida, 1967b:429-436. En este apartado me basaré preferentemente en dos textos de Derrida, ambos publicados en ese annus mirabilis que fue 1967: por un lado, De la Grammatologie; por el otro, los ensayos «Edmond Jabès et la question du libre» $\mathrm{y}$ «Ellipse», ambos recopilados en L'écriture et la différence.

8 Sobre este asunto, cfr., por supuesto, Derrida, 1967c.

9 Sobre el sentido que le doy aquí al término policial, cfr. Rancière, 1995.

10 Para un panorama general sobre la historia de la escritura — aunque no en el sentido derridiano-y su relación con los diversos soportes, cfr. Diringer, 1982; Labarre, 2001; Barbier, 2001. Sobre el impacto de la imprenta en relación con el libro, cfr. el ya clásico estudio de Febvre y Martin, 1958.

11 La idea del Libro como «tejido viviente» $\mathrm{u}$ «organismo» se encuentra en el centro de la cábala: «Que la Torá es un organismo viviente es una noción que se encuentra en la línea de varias corrientes del pensamiento de los cabalistas» (Scholem, 1998:48). En el siglo XX, el gran teólogo Teilhard de Chardin ha propuesto también una metafísica del tejido: «Tejido de una sola pieza, según un único y mismo procedimiento, pero que punto a punto no se repite jamás, la tela del Universo corresponde a una única figura: ella forma estructuralmente un Todo» (1956:39-40).

$12 \mathrm{El}$ proceso por el cual tales enzimas degradan la celulosa se puede resumir en tres pasos: la $ß$-1,4-gluconasa actúa aleatoriamente sobre los enlaces glicosídicos $\beta-1,4$ y, como resultado, disminuye la longitud de las cadenas de celulosa y la creación de nuevos extremos reactivos que servirán como sustrato para reacciones posteriores. La segunda etapa involucra la enzima $\beta$-1,4-glucanasa, que corta la cadena de 1,4- $\beta$-D-glucano del extremo no reductor de la molécula de celulosa y las celodestrinas y que causa la eliminación de unidades de celobiosa o glucosa. Finalmente, en la última etapa, se produce la degradación de la región cristalina después de la degradación de las regiones amorfas gracias a la acción sinérgica de endoglucanasas y exoglucanasa. El resultado es la degradación de la celulosa de la celobiosa a la glucosa por la acción de la $\beta$-1,4-glucosidasa $\mathrm{Cb}$ ya que las glucanasas son inhibidas por la celobiasa. Para una explicación del proceso digestivo del
Lepisma saccharina, crf. Lasker, 1957:123-127. Sobre el Lepisma saccharina en general, cfr. Clark, 1927:190-192. Sobre los restos de seda formados por el Lepisma saccharina durante el proceso de apareamiento, cfr. Walker et al., 2013:572-579.

13 Con la noción de neutro, sin embargo, retomada entre otros por el mismo Derrida, Blanchot se ha arriesgado a pensar aquello que pareciera perderse más allá del pensamiento y del sentido, no en un más allá trascendente, elevado, soberano, sino en una región ajena e irremediablemente obliterada. ¿Será casual que en esa neutralidad, siempre ligada en Blanchot y en Derrida a la escritura, se insinúe la estela evasiva del fantasma?: «Neutro sería el acto literario que no es ni de afirmación ni de negación y (en un primer momento) libera el sentido como fantasma, acoso, simulacro de sentido, como si lo propio de la literatura fuera ser espectral» (1969:448). En mi caso, el fantasma es ajeno tanto a la voz cuanto a la escritura. Sobre este asunto, cfr. las notas 15 y 17 y la conclusión de este artículo.

14 Sobre la noción de «a priori del a priori», cfr. Prósperi, 2019a. 15 Décadas más tarde, Derrida abordará el problema del fantasma en relación al comunismo marxista y adoptará una perspectiva ligeramente diversa a la de sus textos de 1967. En efecto, la idea de fantasma que propone Derrida en Spectres de Marx, mucho más cercana a la concepción de la literatura que intento defender en este artículo, funciona como un operador indecidible e irreductible a las polaridades metafísicas (vidamuerte, presencia-ausencia, sensible-inteligible, etc.). Sobre este asunto, por supuesto, cfr. Derrida, 1993. Sin embargo, como explicaré en breve, el límite de Derrida es que piensa siempre esa indecidibilidad como différance, es decir como un juego proliferante de diferimientos.

16 Tal es así que Jones Irwin propone interpretar la obra derridiana en general como una écriture du corps o writing of the body (cfr. Irwin, 2010).

17 En el ensayo «Platon et le simulacre», Gilles Deleuze sostiene que la verdadera distinción del platonismo no radica en la dicotomía modelo-copia o Idea-imagen, sino entre dos tipos de imágenes: las copias-íconos, dotadas de semejanza y fundadas en las Formas o esencias; los simulacros-fantasmas, repeticiones infundadas de una desemejanza o disparidad. Interesa destacar que, para Deleuze, existe una «diferencia de naturaleza entre simulacro y copia, el aspecto por el cual ellos forman las dos mitades de una división. La copia es una imagen dotada de semejanza, el simulacro una imagen sin 
semejanza» (1969:297). El término phantasma, en consecuencia, designa una entidad irreductible a lo sensible y lo inteligible o a la materia y el espíritu. Así como el Libro, en tanto prototypos y a la vez eikon, aglutina (es decir cose o sutura) lo sensible con lo inteligible, la literatura, en tanto phantasma, los separa y desune. Por razones de extensión, no puedo desarrollar aquí en profundidad la concepción del phantasma que propone Deleuze — análoga en muchos aspectos a la del propio Derrida-y en la cual me baso para pensar la literatura. Me basta con retener solo dos puntos: 1) el phantasma difiere por naturaleza del eikon; 2) el phantasma es ajeno a la dialéctica metafísica del Modelo y la copia.

18 Sobre la crítica de Agamben a la gramatología derridiana, cfr. Attell, 2015:19-39.

19 Para una crítica de la filosofía política de Agamben y de su inspiración benjaminiana, tomando además como eje el ensayo «Zur Kritik der Gewalt», cfr. Prósperi, 2019b:105-121.

20 La condición diferencial o diferida de la ley, y a la vez la imposibilidad de sustraerse a ese juego de retardos y diferimientos, es evidente en la lectura que realiza Derrida del relato kafkiano «Vor dem Gesetz»: «La prohibición presente de la ley no es entonces una prohibición, en el sentido de obligación imperativa, es una différance» (1985:120); y un poco más adelante: «El origen de la différance, he aquí lo que no se debe y no se puede aproximar, presentar, representar y sobre todo penetrar. He aquí la ley de la ley, el proceso de una ley respecto de la cual no se puede jamás decir "hela aquí", aquí o allá» (1985:122). Como puede verse, el planteo de Derrida consiste en mostrar la imposibilidad de sustraerse al juego de la différance, imposibilidad que compartiría, además, con la literatura. (Recuérdese la pregunta retórica que avanza Derrida casi al inicio de su lectura del relato de Kafka: «¿y si la ley, sin ser ella misma atravesada por la literatura, compartiera sus condiciones de posibilidad con la cosa literaria?» (1985:109). Por el contrario, en este artículo afirmamos que la chose littéraire efectúa incluso una fisura en el juego diferencial y abre consecuentemente un afuera respecto a la différance misma.

21 Como puede verse, esta lectura de Agamben pareciera centrarse en el momento de inversión del procedimiento deconstructivo, sin atender al momento de suspensión o desactivación de las oposiciones, razón por la cual el filósofo italiano inscribe a Derrida en la tradición metafísica de la negatividad. Sin embargo, es pertinente atender a la advertencia de Mónica
Cragnolini respecto a no identificar a la deconstrucción con alguna forma de teología negativa: «La différance es lo que no se hace presente, porque hace posible la presentación de lo presente. A veces, pareciera que la forma de hacer referencia a la misma supone una caracterización desde la teología negativa: no es, no es un ser presente, no existe. Sin embargo, esto no posibilita una reapropiación teológica (u ontoteológica) del tema de la différance, porque ella es la que abre el espacio en el que la ontoteología se produce y, en este sentido, también la excede» (2012:19-20). Esta advertencia de Cragnolini, no obstante, me permite precisar mi posición: para Derrida la literatura es un modo de acceder a la différance entendida como el juego diferencial que «abre el espacio en el que la ontoteología se produce», mientras que para mí la literatura es un modo de acceder al afuera de ese juego de diferimientos. Dicho de otro modo: no es que la literatura suspenda solo las oposiciones en las que se estructura la metafísica de la presencia, sino que va más lejos aún y suspende la proliferación diferencial que abre el espacio de esas oposiciones.

22 El párrafo inicial de ese libro notable y perverso que es El árbol de Saussure muestra a la perfección, es decir de modo paródico, la centralidad de la barra en el proceso de significación. El primer apartado, titulado «La barra del bar» (y téngase presente que «barra» en inglés se dice «bar», con lo cual podría leerse «la barra de la barra»), comienza así: «Con los codos apoyados en la barra de metal, los parroquianos del ghetto miran con mirada boba el único árbol de la plaza, sin imaginar siquiera que el bar donde se encuentran proviene, casualmente, de barra» (Libertella, 2000:15).

23 De más está decir que esta ruptura de la cadena significante, sumada a la ruptura correlativa de la relación de cada significante con su significado, es el aspecto distintivo, al menos para el psicoanálisis lacaniano, de la esquizofrenia. Permítaseme citar a propósito un esclarecedor pasaje de Fredric Jameson: «Cuando esta relación se rompe, cuando los enlaces de la cadena significante se interrumpen, entonces surge la esquizofrenia bajo la forma de un conglomerado de significantes distintos e inconexos. (...) Si somos incapaces de unificar el pasado, el presente y el futuro de la sentencia, entonces somos también incapaces de unificar el pasado, el presente y el futuro de nuestra propia experiencia biográfica o vida psíquica. Con el derrumbe de la cadena significante, por lo tanto, el esquizofrénico se ve reducido a una experiencia de puros significantes 
materiales, o, en otras palabras, a series de presentes puros e inconexos en el tiempo» (1991:27). Como ha mostrado Deleuze, la literatura es un asunto de critique et clinique.

24 La acción traumática de la literatura encuentra su momento «simbólico» en Mallarmé: tanto en la idea de un Libro (imposible) cuanto en la preeminencia que posee la materialidad de la página, es decir el soporte en cuanto tal, en el discurrir de los signos. Como ha dicho Héctor Ciocchini en relación a Coup de dés: «El espacio de la página, equivalente analógico del espacio mental, reproduce además las alternancias, las detenciones, el ritmo íntimo del pensamiento» (2010:47-48). Y es sobre este espacio, sobre el soporte mismo en el que descansa la cadena significante, análoga al ritmo del stream of counsciousness, que opera la literatura produciendo una arritmia generalizada que es el análogo, al nivel del pensamiento, al efecto producido por la apnea en el ritmo de la respiración. Sobre los conceptos de «apnea» y de «respiración» desde una perspectiva ontológica, cfr. Prósperi, 2018.

25 En efecto, como he indicado, Blanchot es uno de los autores contemporáneos que ha ido más lejos a la hora de afrontar —y asumir — las paradojas y ambigüiedades de un pensamiento de lo neutro. En Le Pas au-delà, por ejemplo, explica el sentido específico del término: «Lo neutro deriva, del modo más simple, de una negación con dos términos: neutro, ni lo uno ni lo otro. Ni ni lo otro, nada más preciso» (1973:104). Lo neutro posee sin dudas una relación íntima con la nada, pero no con la nada en tanto opuesta —y por lo tanto reductible — al ser, sino la nada que se mantiene más allá del ser, allende al ser, irrecuperable. Como explica Marlène Zarader: «La nada es allí, seguramente, satura la visión (en la fascinación), pero no es ni visible $n i$ invisible, $n i$ rechazada ni dada, ni oculta ni manifiesta. Ser expuesto a ella, es ser «en una relación que no abre la luz, que no cierra la ausencia de luz». En tanto que tal, esta relación puede y debe ser dicha "neutra"» (2001:172; las cursivas son de Zarader).

26 Sobre la noción de «post-hantología», cfr. Ludueña Romandini, 2016:197-209.

27 La noción de «cuasi-trascendental» designa, en el pensamiento de Derrida, una instancia que funciona como condición de posibilidad y a la vez de imposibilidad de un fenómeno. Sobre esta noción en Derrida, cfr. Hurst, 2004:244-266.

28 En un artículo importante, Suzanne Saïd ha señalado el nexo indiscutible que existe entre eikon y symbolon, a la vez que el nexo, también indiscutible, entre eidolon y phantasma: «Se conforma así una oposición entre dos definiciones de la imagen: el eidolon, que es un simulacro, y el eikon, que es un símbolo» (1987:322).

\section{Referencias}

Agamben, G. (1979). Stanze. La parola e il fantasma nella cultura occidentale. Torino: Einaudi.

Agamben, G. (1982). Il linguaggio e la morte. Un seminario sul luogo della negatività. Torino: Einaudi.

Attell, K. (2015). Giorgio Agamben. Beyond the Threshold of Deconstruction. New York: Fordham University Press.

Barbier, F. (2001). Histoire du libre en Occident. París: Armand Colin.

Blanchot, M. (1955). L'espace littéraire. París: Gallimard.

Blanchot, M. (1969). L'entretien infini. París: Gallimard.

Blanchot, M. (1973). Le Pas au-delà. París: Gallimard.

Blumenberg, H. (1984). La leggibilità del mondo. Il libro come metafora della natura. Bologna: Il Mulino.

Brooke, J.H. (2014). Science and Religion. Some Historical Perspectives. Cambridge: Cambridge University Press.

Ciocchini, H. (2010). Temas de crítica y estilo. Bahía Blanca: 17Grises.

Clark, C.O. (1927). The Silverfish, an Insect attacking Sized Textile Fibres. Coloration Technology, (43), 190-192.

Cragnolini, M.B. (1996). Nietzsche-Huidobro-Aschenbach: azores fulminados por la altura. Confines, (3), 185-198.

Cragnolini, M.B. (2012). Derrida. Un pensador del resto. Buenos Aires: La Cebra.

Curtius, E.R. (1983). European Literature and the Latin Middle Ages. Princeton, Oxford: Princeton University Press. 
Deleuze, G. (1968). Différence et répétition. París: P.U.F.

Deleuze, G. (1969). Logique du sens. París: Éditions de Minuit.

Deleuze, G. (1993). Critique et clinique. París: Éditions de Minuit.

Derrida, J. (1967a). De la Grammatologie. París: Éditions de Minuit.

Derrida, J. (1967b). L'écriture et la différence. París: Éditions du Seuil.

Derrida, J. (1967c). La voix et le phénomène. París: P.U.F.

Derrida, J. (1972). Marges de la philosophie. París: Éditions de Minuit.

Derrida, J. (1985). Préjugés. Devant la loi. En Derrida, J. et all. La Faculté de Juger. Colloque de Cerisy (87-139). París: Éditions de Minuit.

Derrida, J. (1993). Spectres de Marx. L'État de la dette, le travail du deuil et la nouvelle Internationale. París: Galilée.

Derrida, J. (2003). Psyché, Inventions de l'autre. Tomo 2. París: Galilée.

Diringer, D. (1982). The book before printing: ancient, medieval, and oriental. New York: Dover Publications.

Febvre, L. y Martin, H.-J. (1958). L'apparition du livre, tome I. París: Éditions Albin Michel.

Hooke, R. (1665). Micrographia: Or some Physiological Descriptions of Minute Bodies made by Magnifying Glasses. London: Martyn \& Allestry.

Hurst, A. (2004). Derrida's Quasi-Transcendental Thinking. South African Journal of Philosophy, 23(3), 244-266.

Idel, M. (1989). Language, Torah, and Hermeneutics in Abraham Abulafia. New York: State University of New York Press.

Idel, M. (2002). Absorbing Perfections. Kabbalah and Interpretation. New Haven, London: Yale University Press.

Idel, M. (2003). Jacques Derrida et les sources kabbalistiques. En Cohen, J. y Zagury-Orly, R. (dirs.): Judéités. Questions pour Jacques Derrida (133-156). París: Galilée.

Irwin, J. (2010). Derrida and the Writing of the Body. Surrey: Ashgate.

Jameson, F. (1991). Postmodernism, Or the Cultural Logic of Late Capitalism. Durham: Duke University Press.

Kojève, A. (1979). Introduction à la lecture de Hegel. París: Gallimard.

Labarre, A. (2001). Histoire du libre. París: P.U.F.

Lasker, R. (1957). Silverfish, a Paper-Eating Insect. The Scientific Monthly, 84(3), 123-127.

Libertella, H. (2000). El árbol de Saussure. Buenos Aires: Adriana Hidalgo.

Ludueña Romandini, F. (2016). Principios de espectrología. La comunidad de los espectros II. Buenos Aires: Miño y Dávila Editores.

Prósperi, G.O. (2018). La respiración del Ser. Apnea y ensueño en la filosofía hegeliana. Buenos Aires: Miño y Dávila.

Prósperi, G.O. (2019a). La máquina óptica. Antropología del fantasma y (extra)ontología de la imaginación. Buenos Aires: Miño y Dávila.

Prósperi, G.O. (2019b). Preferiría no firmar... Sobre algunos problemas políticos en la filosofía de Giorgio Agamben. Contrastes. Revista Internacional de Filosofía, XXIV(1), 105-121.

Rancière, J. (1995). La Mésentente. Politique et philosophie. París: Galilée.

Saïd, S. (1987). Deux noms de l'image en grec ancien: idole et icône. Comptes rendus des séances de l'Académie des Inscriptions et Belles-Lettres, 131-132, 309-330.

Saussure, F. de (1995). Cours de linguistique générale. París: Éditions Payot \& Rivages.

Scholem, G. (1998). La cábala y su simbolismo. México: Siglo XXI.

Tanzella-Nitti, G. (2001). The Book of Nature and the God of Scientists according to the Encyclical Fides et Ratio. The Human Search for Truth: Philosophy, Science, Faith. The Outlook for the Third Millennium (85-92). Philadelphia: St. Joseph's Univ. Press. 
Tanzella-Nitti, G. (2005). The Two Books Prior to the Scientific Revolution. Perspectives on Science and Christian Faith, 57(3), 235-248.

Teilhard de Chardin, P. (1956). Le phénomène humain. París: Les Éditions du Seuil.

Walker, A. et all. (2013). Silverfish silk is formed by entanglement of randomly coiled protein Chains. Insect Biochemistry and Molecular Biology, 43(7), 572-579.

Zarader, M. (2001). L'être et le neutre. À partir de Maurice Blanchot. París: Éditions Verdier. 